\title{
A Codificação Municipal de Florianópolis
}

\author{
A. Delorenzo Neto \\ Professor no Instituto de Estudos Municipais \\ da Escola de Sociologia e Política de São \\ Paulo
}

\begin{abstract}
A mais complexa codificação municipal vigente no País é a de Florianópolis, aprovada pela Lei n. $^{\circ} 246$ de 15 de novembro de 1955 , louvável iniciativa do Prefeito OSMaR CunHa. Com efeito, nêsse texto redobramos nossos esforços em apurar as ncrmas e estender ao máximo o campo da competência própria do Município. Seguimos rigorosamente nossa metodologia, que comporta as seguintes fases: $1 .^{a}$ ) estudo global da legislação; $2 .^{a}$ ) separação da legislação vigente da não vigente; $3 .^{a}$ ) classificação dos textcs aproveitáveis; $4 .^{a}$ ) incorporação das inovações necessárias; $5^{a}{ }^{a}$ ) crítica e comparação e $6^{a}$ ) redação final. No novo Código de Florianópolis, que abrange 1.941 artigos (o que o torna a maicr lei brasileira), apurou-se acentuadamente o rigor lógico na classificação das matérias. E, sobretudo, no seu desenvolvimento emprestou-se especial atenção à teoria sociológica dos Municípios, (*) no sentido de alargar jurìdicamente a sua competência - fugindo das vias clássicas da mera delegação do Estado - para colocá-lo na plenitude de sua aptidão institucional.
\end{abstract} segue:

A técnica de seu ordenamento poderá ser analisada no esquema que

CÓDIGO MUNICIPAL DE FLORIANÓPOLIS

PARTE GERAL

Disposições Preliminares

LIVRO I

DA APLICAÇÃO DO DIREITO MUNICIPAL

Tí́tuLo ÚNICO

Capítulo I - Das infrações e das penas

Capítulo II - Dos autos de.infração

Capítulo III - Do processo de execução

(*) cf. Carmona Romay, Adriano - La Autonomia Financiera Municipal a la luz de la Teoria Sociológica del Municipio, Madrid, 1955. 


\title{
LIVRO II
}

\section{DO PODER DE POLICIA}

\author{
Título I
}

\section{DAS NORMAS DE URBANISMO}

Capítulo I - Do plano diretor

Capitulo II - Do zoneamento

Capítulo III - Dos arruamentos

Capítulo IV - Dos loteamentos

Capítulo V - Dos reloteamentos

Capítulo VI - Do desmembramento

Capítulo VII - Das vias e logradouros públicos

\section{Título II}

\section{DAS NORMAS SÔBRE OBRAS}

Capítulo I - Dos profissionais habilitados a projetar, calcular e construir Capítulo II - Da licença e projetos

$$
\begin{gathered}
\text { Seção I - Das normas gerais } \\
\text { Seção II - Do projeto }
\end{gathered}
$$

Seção III -- Das condições para concessão das licenças para obras parciais Seção IV - Do processamento e expedição das licenças, cancelamentos e revalidação da aprovação dos projetos

Capítllo III - Das obrigações para execução de obras

Seção I - Do destino do alvará do projeto aprovado - exame de concreto - conclusão de obras

Seção II - Das obras paralisadas - demolições

Capítulo IV - Das normas para o cálculo das construções

Seção I - Das solicitações máximas das fundações

Seção II - Das cargas de segurança para materiais

Seção III - Das cargas de segurança para edifícios

Seção IV - Do cálculo e execução das obras de concreto armado

Capítulo V - Da edificação dos lotes

$$
\begin{aligned}
& \text { Seção I - Dos lotes } \\
& \text { Seção II }- \text { Das construções } \\
& \text { Seção III }- \text { Das vilas }
\end{aligned}
$$

Capítulo VI - Dos materiais de construção

Capítulo VII - Dos tapumes e andaimes

Capítulo VIII - Das partes componentes das construções e outras condições

Seção I - Do alinhamento e soleira

Seção II - Do revestimento do solo

Seção III - Das fundações

Seção IV - Dos pisos

Secão V - Das paredes

Seção VI - Da cobertura

Seção VII - Das chaminés

Seção VIII - Dos compartimentos

Subseção I - Da classificação dos compartimentos

Subseção II - Das condições dos compartimentos 
Subseção III - Da subdivisão dos compartimentos

Subseção IV - Da iluminação e ventilação

Seção IX - Dos tanques de lavagem

Seção X - Das instalações de águas e esgotos

Subseção I - Do abastecimento domiciliário de água

Subseção II - Dos esgotos domiciliares

Seção XI - Das instalações elétricas

Seção XII - Dás instaleçòes e apareihamento contra incêndio

Seção XIII - Das instalações mecânicas

Subseção II - Das condições para a instalação dos geradores a vapor

Subseção III - Da fiscalização das instalações mecânicas

Subseção IV - Da baixa das instalaçỗes mecânicas

Subseção V - Das instalações de elevadores

Subseção VI - Das condições de funcionamento dos elevadores

Seção XIV - Dos jiraus, porões e sótãos

Seção $\mathrm{XV}-\mathrm{Da}$ arquitetura dos edifícios

Subseção I - Das fachadas

Subseção II - Das marquizes

Subseção III - Das vitrines e mostruários

Subseção IV - Dos anúncios e letreiros

Capitulo IX - Das construções destinadas a fins especiais

Seção I - Das habitações coletivas em geral

Seção II - Dos prédios de apartamento

Seção III - Dos estabelecimentos de trabalho

Subseção I - Das normas gerais

Subseção II - Das fábricas e grandes oficinas

Subseção III - Das garagens comerciais e oficinas para automóveis

Subseçáo IV - Dos postos para abastecimento de automóveis

Subseção V - Das padarias e confeitarias

Subseção VI - Dos açougues

Subseção VII - Das destilarias, fábricas de bebidas e cervejas e estabelecimentos congêneres

Subseção VIII - Dos frigoríficos e fábricas de gêlo

Seção IV - Dos estabelecimentos comerciais e industriais de leite e laticínios

Subseção I - Das granjas leiteiras.

Subseção II - Das . usinas de beneficiamento

Subseção III - Dos postos de refrigeração

Subseção IV - Dos entrepostos de leite

Subseção V - Das fábricas de laticínios

Subseção VI - Das leiterias

Seção V - Dos hotéis

Seção VI - Dos hospitais

Seção VII - Das casas ou locais de reunião

Subseção I - Das normas gerais

Subseção II - Dos cinemas

Subseção III - Dos teatros

Subseção IV - Dos circos e parques de diversões

Secão VIII - Das piscinas de natação

Seção IX - Das colônias de férias e acampamentos em geral

Secão X - Dos estábulos e estrebarias

Seção XI - Dos necrotérios e necrocômios 
TíTULO III

\section{DISPOSIÇÕES GERAIS}

Capítulo I - Das habitações operárias

Capítulo II - Das casas de madeira

Capítulo III - Da numeração de prédios

Capítulo IV - Dos passeios

Capítulo V - Do fechamento e conservação de terrenos

Seção I - Dos terrenos não construídos

Seção II - Dos terrenos construídos

Seção III - Das muralhas de sustentação

Capítulo VI - Dos tapumes e fechos divisórios

Capítulo VII - Das construções na zona rural Capítulo VIII - Das penalidades

\section{Título IV}

DAS MEDIDAS DE SEGURANÇA PÚBLICA

Capítulo I - Do empachamento

Seção I - Do* empachamento transitório

Subseção II - Dos andaimes

Subseção III - Da descarga de material na via pública

Seção II - Do empachamento permanente

Subseção I - Da arborização

Subseção II - Dos postes telegráficos, telefônicos, de iluminação e fôrça; avisadores de incêndio e de polícia; caixas postais e balanças

Subseção III - Das colunas ou suportes de anúncios - caixas de papéis, usados, bancos - abrigos e barracas

Subseção IV - Das bancas de jornais

Subseção V - Das mesas e cadeiras

Subseção VI - Dos relógios públicos, estátuas, fontes, monumentos, etc.

Seção III - Do empachamento aéreo

Capítulo II - Dos inflamáveis e explosivos

Capítulo III - Das queimadas

\section{Título V}

\section{DA POLÍCIA SANITÁRIA}

Capítulo I - Disposições gerais

Capítulo II - Da higiene das vias públicas

Capítulo III - Da higiene das habiteções

Capítulo IV - Da higiene da alimentação

\section{Título VI}

\section{DA POLICIA DE ORDEM POBLICA}

Capítulo I - Dos costumes, da tranqüilidade de habitantes e dos divertimentos públicos

Seção I - Das atividades comerciais

Subseção I - Das normas gerais

Subseção II - Do comércio localizado 
Subseção III - Do comércio ambulante

Subseção IV - Dos agenciadores

Subseção V - Dos carregadores

Subseção VI - Dos jornaleiros

Subseção VII - Dos anúncios e propagandas

Seção II - Das atividades industriais

Capitulo IV - Das medidas referentes aos animais e à extinção dos insetos nocivos

LIVRO III

DO REGIMEN TRIBUTÁRIO

Título I

DOS TRIBUTOS EM GERAL

Capítulo I - Disposições preliminares

Capitulo II - Das isenções

Capítulo III - Das restituições

Capitulo IV - Do arbitramento

Capítulo V - Das penalidades

Capítulo VI - Dos recursos

Capítulo VII - Do cadastro imobiliário

Capítulo VIII - Das normas da revisão dos tributos

Capitulo IX - Da dívida ativa

Seção I - Das normas gerais

Seção II - Da revisão da dívida e classificação dos devedores

Seção III - Da liquidação da dívida

Seção IV - Da prescrição

Título II

DOS IMPOSTOS

Capítulo I - Do impôsto predial urbano

Seção I - $\mathrm{Da}$ incidência

Seção II - Do valor locativo

Seção III - Do lançamento e avaliação

Seção IV - Da arrecadação

Capítulo II - Do impôsto territorial urbano

Seção I - Da incidência

Seção II - Do lançamento

Seção III - Da arrecadação

Seção IV - Das áreas urbanizadas por emprêsas imobiliárias

Capítulo III — Do impôsto de licença

Seção I - Disposições gerais

Subseção I - Da incidência

Subseção II - Do lançamento e arrecadação

Seção II - Da licença para localização de estabelecimentos comerciais, industriais, profissionais e similares

Seção III - Da licença para o trânsito de veículos 


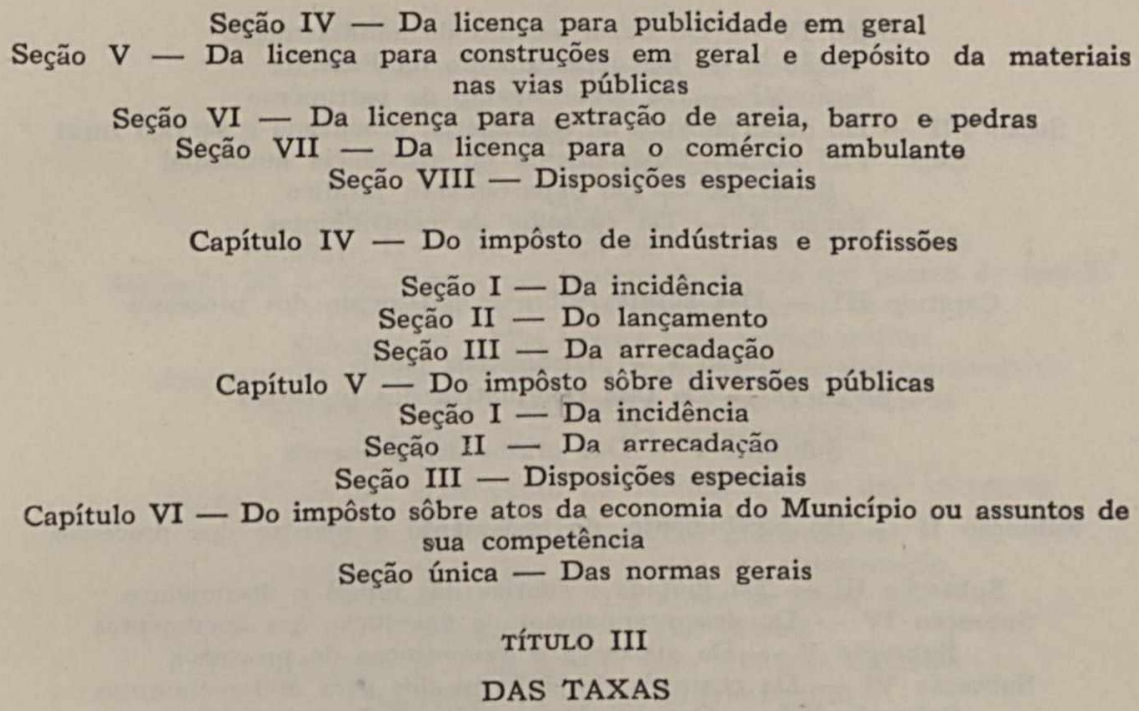

Capítulo I - Da taxa de numeração de prédios

Capítulo II - Da taxa de limpeza pública

Capítulo III - Da taxa sôbre o serviço do matadouro

Capítulo IV - Da taxa de mercado

Capítulo V - Da taxa de localização nas feiras-livres

Capítulo VI - Da taxa de aferição de pesos e medidas

Capítulo VII - Da taxa de turismo e hospedagem

Capítulo VIII - Da taxa de matrícula de cães

Capítuio IX - Da taxa de arrecadação de bens móveis ou semoventes ao depósito municipal

Capítulo $\mathrm{X}$ - Da taxa de ambulância municipal

Capítulo XI - Da taxa funerária

Capítulo XII - Da taxa de fiscalização de obras

Capítulo XIII - Da taxa de execução de calçamento

Capítulo XIV - Da taxa de melhoramentos

Capítulo XV - Da taxa de viação

TíTuLO IV

DA RENDA PATRIMONIAL

Capítulo único - $\mathrm{Da}$ incidência e da arrecadação

PARTE ESPECIAL

LIVRO I

DA ADMINISTRAÇÃO MUNICIPAL

Tírulo I

DA ORGANIZAÇÃo DOS SERVIÇOS

Capítulo I - Das normas gerais

Capítulo II - Das atribuições

Seção I - Do Prefeito

Seção II - Das atribuições gerais de chefia

Seção III - Do gabinete do Prefeito 
Seção IV - Do departamento de administração

Seção V - Do departamento da Fazenda

Seção VI - Do departamento do patrimônio

Seção VII - Do departamento de engenharia, urbanismo e serviço rural

Seção VIII - Do departamento de assistência municipal

Seção IX - Do departamento jurídico

Seção $\mathrm{X}$ - Do conselho de contribuintes

Capítulo III - Das normas sôbre o andamento dos processos

Seção I - Disposições gerais

Seção II - Da fase informativa dos processos

Subseção I - Dos prazos dos processos

Subseção II - Do recebimento, do andamento e registro dos processos

Subseção III - Da juntada e rubrica das fôlhas e documentos

Subseção IV - Do desentranhamento e devolução dos documentos

Subseção $\mathrm{V}$ - Da anexação e desanexação de processos

Subseção VI - Da chamada dos interessados para esclarecimentos

Subseção VII - Das diligências, informações e pareceres

Seção III - Da fase decisória dos processos

Subseção I - Do despacho

Subseção II - Da publicação e execução dos despachos

Seção IV - Do processamento dos recursos

Seção V - Do arquivamento dos processos

Subseção I - Do tempo e modo de arquivamento

Subseção II - Do novo trânsito de papéis arquivados

Subseção III - Do contrôle do arquivamento sôbre processos a arquivar

Tí́tuLo II

DOS FUNCIONÁRIOS MUNICIPAIS

Capítulo I - Disposições gerais

Capítulo II - Do provimento e vacância

Seção I - Do provimento

Seção II — Da nomeação

Subseção I - Disposições preliminares

Subseção II - Do recurso

Subseção III - Da posse

Subseção IV - Da fiança

Subseção V - Do exercício

Seção III - Da promoção

Seção IV - Da transferência e remoção

Seção V - Da reintegração

Seção VI — Da readmissão

Seção VII - Do aproveitamento

Seção VIII - Da reversão

Seção IX - Da readaptação

Seção X - Da substituição

Seção XI - Da permuta

Seção XII - Da vacância 


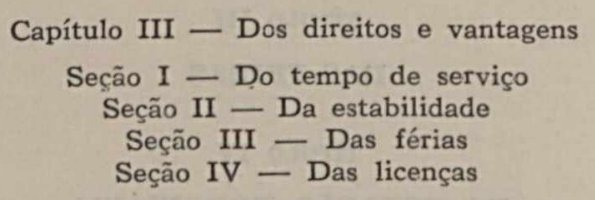

Subseção I - Disposições preliminares

Subseção II - Da licença para tratamento de saúde

Subseção III - Da licença por motivo de doença em pessoa da família

Subseção IV - $\mathrm{Da}$ licença à gestante

Subseção $\mathrm{V}$ - Da licença para serviço militar

Subseção VI - Da licença para trato de interêsses particulares

Subseção VII - Da licença à funcionária casada

Subseção VIII - Da licença-prêmio

Seção V - Do vencimento ou remuneração e das vantagens

Subseção I - Disposições preliminares

Subseção II - Do vencimento ou remuneração

Subseção III - Da ajuda de custo

Subseção IV - Das diárias

Subseção V - Do auxílio para diferença de caixa

Subseção VI — Do salário-família

Subseção VII - Do auxílio-doença

Subseção VIII - Das gratificações

Subseção IX - Da representação

Seção VI - Das concessões

Seção VII - Da assistência

Seção VIII - Do direito de petição

Seção IX - Da disponibilidade

Seção $\mathrm{X}-\mathrm{Da}$ aposentadoria

Capítulo IV - Do regime disciplinar

Seção I - Da acumulação

Seção II - Dos deveres

Seção IV - Da responsabilidade

Seção V - Das penalidades

Seção VI - Da prisão administrativa

Seção VII - Da suspensão preventiva

Capítulo V - Do processo administrativo e sua revisão

Seção I - Do processo

Seção II - Da revisão

Capítulo VI - Disposições especiais

\section{LIVRO II} DAS NORMAS COMPLEMENTARES DE REGULAMENTAÇÃO
TÍTULO I

DO ABASTECIMENTO DE CARNE VERDE

Capítulo I - Disposições gerais

Capítulo II — Da matança e inspeção sanitária

TÍTULO II

DOS MERCADOS

Capitulo I - Da utilização

Capítulo II - Da localização de cômodos

Capítulo III - Do comércio em áreas abertas 
TÍTULO III

DAS FEIRAS

TítuLo IV

DA ESTAÇÃO RODOVIÁRIA

Tí́tULO V

DA UTILIZAÇÃO DOS VEÍCULOS DA PREFEITURA

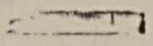

Título VI

DO FUNCIONAMENTO DE ALTO-FALANTES

Título VII

DA COOPERAÇÃO FINANCEIRA COM ENTIDADES PRIVADAS

TÍTULO VIII

DOS CEMITÉRIOS PÚBLICOS

Capítulo I - Disposições gerais

Capítulo II - Das inumações

Capítulo III - Das construções

TítuLO IX

DOS SERVIÇOS DE UTILIDADE PUBLICA

Capítulo I - Das normas gerais

Capítulo II - Da concessão de serviços de transporte coletivo

Título $\mathrm{X}$

DOS BENS

Capítulo único - Das classes de bens

Seção I - Dos bens móveis e imóveis

Seção II - Da venda de terrenos do patrimônio municipal

Subseção I - Da venda em geral

Subseção II - Da hasta pública para a venda

Subseção III - Dos lotes edificados

Título XI

DO SANEAMENTO RURAL

\section{DISPOSIÇÕES TRANSITÓRIAS}

Capítulo I - Disposições preliminares

Capítulo II - Da planificação municipal

Seção I - Das condições mínimas

Seção II - Dos recursos financeiros

DISPOSIÇÕES FINAIS 